\title{
Desafios da Gestão Coletiva da Atividade na Docência Universitária $^{1}$
}

\author{
Challenges Of The Collective Management \\ Activity In The Universitary Docency
}

Desafíos De La Gestión Colectiva De La Actividad En La Docencia Universitaria
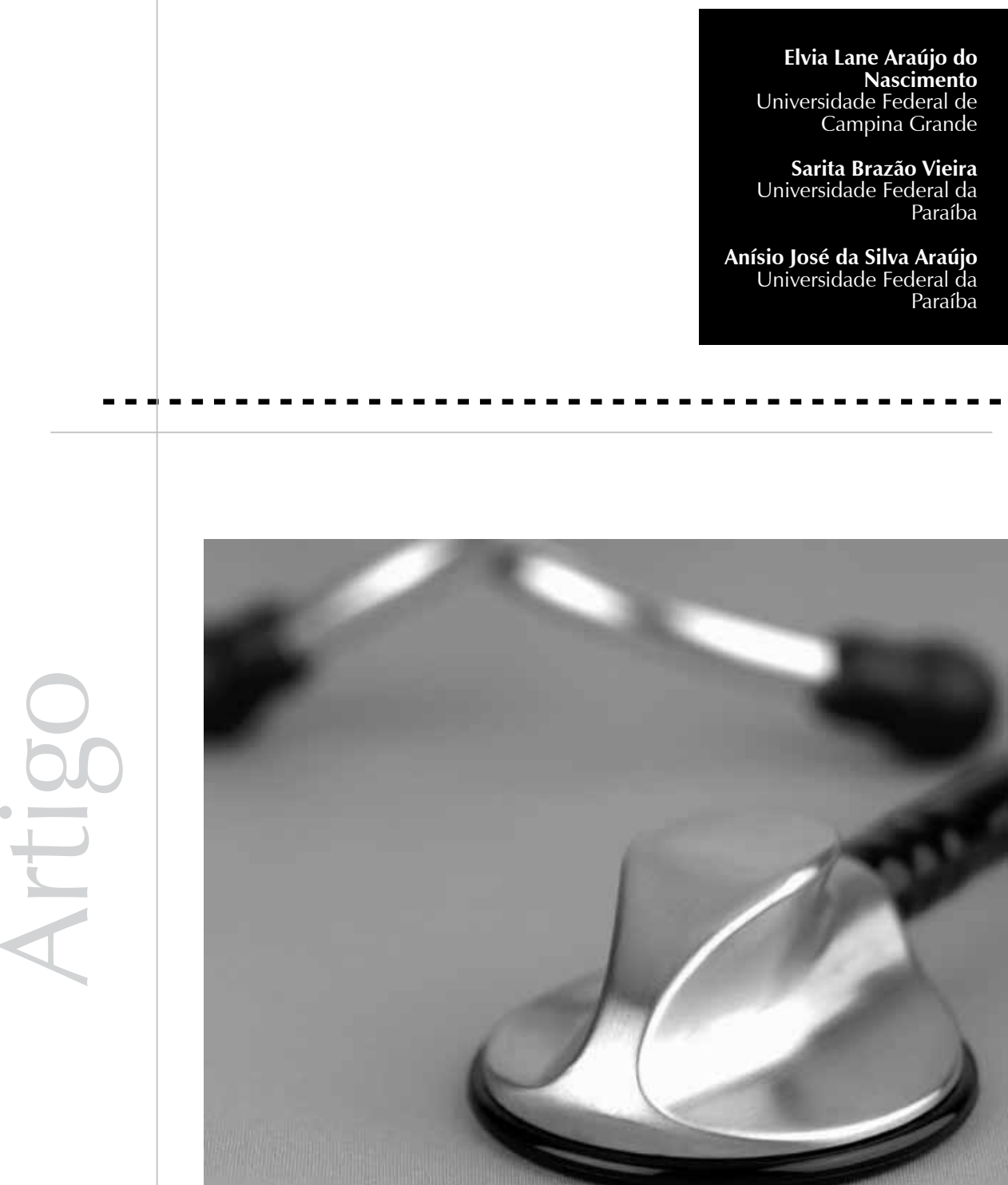
Resumo: Este artigo objetiva analisar questões relativas à gestão coletiva da atividade docente no curso de Medicina de uma instituição federal de ensino superior, evidenciadas pela avaliação externa realizada pelo Ministério da Educação (MEC), e seu referencial teórico baseia-se nas abordagens da ergonomia e da psicodinâmica do trabalho. Trata-se de um estudo qualitativo do qual participaram dez docentes, oito homens e duas mulheres, de um total de cento e quarenta e nove existentes no curso de Medicina. O critério que serviu de base à composição desse grupo de pesquisa foi ter participado do processo de avaliação do curso de Medicina. Este estudo cumpriu as exigências éticas pertinentes à investigação que envolve seres humanos e sua estratégia metodológica combinou a realização de entrevistas não diretivas, gravadas sob autorização dos entrevistados, com a análise documental de relatórios de avaliação. Os resultados apontaram um engajamento profissional aquém do desejado em atividades de pesquisa e extensão e uma organização do trabalho que dificulta a consolidação dos coletivos e a manutenção de laços de cooperação entre os docentes, aspectos fundamentais para a qualidade e a produtividade, com saúde e segurança no trabalho. Palavras-chave: Tarabalho docente. Educação médica. Ensino superior. Engenharia dos fatores humanos. Psicodinâmica do trabalho.

Abstract: This article aims to examine issues of collective management of teaching activities in the course
of medicine of a federal institution of undergraduation, evidenced by the external evaluation conducted
by the Ministry of Education (MEC), and The theoretical contributions were based on ergonomics and
psychodynamics of work. It is a qualitative study attended by ten professors, eight men and two women,
out of one hundred and forty-nine professors in Medicine. The criterion for the composition of the research
group was the participation in the evaluation process of the medical school. This study followed the ethical
requirements relevant to research involving human beings, and its methodological strategy combined non-
directive interviews, recorded with the permission of the interviewees, with the documentary analysis of
evaluation reports. The results pointed to a professional engagement that stays behind others in research
and extension activities, and a work organization that hinders the consolidation of collectives and the
maintenance of cooperative ties between teachers, key aspects of the issue of quality and productivity,
with health and safety at work. Keywords: Teacher work, Medical education. Higher education. Human factors engineering. Psychodynamics of work.

Resumen: Este artículo tiene el objetivo de analizar cuestiones relativas a la gestión colectiva de la actividad docente en el curso de Medicina de una institución federal de enseñanza superior, evidenciadas por la evaluación externa realizada por el Ministerio de la Educación (MEC), y su referencial teórico se basa en los abordajes de la ergonomía y de la psicodinámica del trabajo. Se trata de un estudio cualitativo del cual participaron diez docentes, ocho hombres y dos mujeres, de un total de ciento cuarenta nueve existentes en el curso de Medicina. El criterio que sirvió de base para la composición de ese grupo de estudio fue haber participado del proceso de evaluación del curso de Medicina. Este estudio cumplió las exigencias éticas pertinentes a la investigación que involucra a seres humanos y su estrategia metodológica combinó la realización de entrevistas no directivas, grabadas bajo autorización de los entrevistados, con el análisis documental de informes de evaluación. Los resultados apuntaron un compromiso profesional por debajo de lo deseado en actividades de investigación y extensión y una organización del trabajo que dificulta la consolidación de los colectivos y el mantenimiento de lazos de cooperación entre los docentes, aspectos fundamentales para la calidad y la productividad, con salud y seguridad en el trabajo.

Palabras Ilave: Trabajo docente. Educación médica. Educación superior. Ingenieria de factores humanos. Psicodinámica del trabajo.

1 Este artigo se baseou na dissertação de mestrado da primeira autora: Avaliação do Trabalho Docente no Curso de Medicina da UFPB: Atividade e Saúde Mental, defendida no PPGEP - Programa de Pós-Graduação em Engenharia de Produção da UFPB.
Nos últimos anos, o trabalho docente tem sido objeto de investigação de diversas disciplinas acadêmicas. Aspectos relativos à organização e às condições de trabalho, mudanças nos processos de trabalho e a relação trabalho docente e saúde são alguns dos temas abordados nesses estudos (Brito, Athayde, \& Neves, 2003; Alvarez, 2004; Morosini, 2004).
No entanto, a docência universitária, quando comparada a outros campos de atuação docente, ainda é pouco problematizada, especialmente quando se consideram, como no caso da Medicina, os novos parâmetros de ensino propostos nas novas Diretrizes Curriculares.

O objetivo do presente artigo é analisar 
algumas questões relativas à gestão coletiva da atividade docente evidenciadas no processo de avaliação externa do curso de Medicina de uma IFES realizada pelo MEC. Este se justifica pela necessidade de aprofundar algumas especificidades do trabalho docente universitário, especialmente quanto às relações entre organização do trabalho e coletivos de trabalho.

O artigo está estruturado do seguinte modo: de início, procura-se evidenciar alguns atributos que singularizam o trabalho docente em Medicina. Na sequência, apresenta-se o Sistema Nacional de Avaliação do Ensino Superior (SINAES), situando-se logo após as reflexões teóricas sobre a dimensão coletiva do trabalho, tecidas a partir de algumas abordagens clínicas do trabalho. Depois, apresenta-se o método adotado no estudo, seguido da análise do material empírico. Por fim, são feitas algumas considerações de modo a contribuir para o aprofundamento do debate em torno da temática da gestão coletiva da atividade.

\section{A especificidade da docência em medicina: "quem sabe fazer, sabe ensinar"}

Diferentemente dos docentes de outros níveis de ensino, a função de professor universitário se constituiu, historicamente, tendo como referência uma profissão exercida de forma paralela no mundo do trabalho. Desse modo, o recrutamento e a seleção de docentes para as universidades eram sustentadas pela lógica do "quem sabe fazer, sabe então ensinar", ou seja, ensinando como foram ensinados, repassando sua experiência, os docentes universitários garantiriam uma transmissão mais ou menos eficiente de saberes e uma socialização dos conhecimentos adquiridos, ao mesmo tempo em que reproduziriam o modelo por meio do qual foram formados (Cunha \& Leite, 1996).
Com o passar do tempo, entretanto, a docência universitária passou a exigir qualificações e competências que o modelo da experiência profissional ou do dom, dos modos tradicionais de inserção e de permanência nas universidades, não estava aparelhado para fornecer. $\mathrm{Na}$ atualidade, por exemplo, exige-se dos docentes universitários, além das qualificações de Mestre e Doutor, a manutenção de uma produção acadêmica regular que contemple o princípio da indissociabilidade entre ensino, pesquisa e extensão. Não obstante, as medidas de produtividade recaem mais acentuadamente sobre a produção científica (Machado \& Magalhães, 2002), valorizandose a quantidade de publicações, fato que introduz um desequilíbrio na equação da indissociabilidade.

No âmbito da educação pública superior, constata-se uma importação dos critérios de desempenho da esfera privada, fenômeno que Silva Júnior e Sguissardi (como citado em Silva, 2009) denominaram mercantilização da universidade estatal pública. O produtivismo acadêmico, que resulta de tal lógica, naturaliza a “(...) sobrevalorização de indicadores e resultados supostamente quantificáveis e mensuráveis" (2009, p.7). A intensificação do trabalho, efeito disso, "(...) é suficiente para deslocar o equilíbrio psíquico e psicossomático desse trabalhador, induzindo a grande maioria ao estresse e às doenças psicossomáticas daí decorrentes (...)" (2009, p.14).

No caso da docência em Medicina, algumas particularidades merecem ser observadas, a saber: (a) a pouca importância dispensada à preparação pedagógica, posto que os cursos médicos, em geral, não contemplam, em seus currículos, disciplinas pedagógicas que desenvolvam competências para o planejamento e o desenvolvimento de atividades de ensino-aprendizagem, (b) a atividade docente é, normalmente, complementar e secundária à prática 
médica propriamente dita, (c) predomina, ainda, o baixo investimento em cursos de pós-graduação como qualificação para as atividades de ensino, pesquisa e extensão (Moré \& Gordan, 2004).

Constatações dessa natureza são corroboradas por diversos estudos sobre a situação do ensino médico no Brasil e também pelos órgãos representativos dos professores de Medicina, dentre os quais se destaca a Associação Brasileira de Ensino Médico (ABEM) (Lampert, 2001; Sá Jr., 2002).

A preocupação fundamental reside na necessidade de implementar mudanças compatíveis com as exigências preconizadas pelas novas Diretrizes Curriculares Nacionais dos cursos de graduação em Medicina, que propõem um modelo de formação voltado para as demandas sociais em saúde (prevenção e promoção), tendo como referência os princípios do Sistema Único de Saúde (SUS), em substituição ao paradigma tradicional das sínteses diagnósticas baseado em evidências, nas especialidades e no modelo hospitalocêntrico de internações (Amoretti, 2005).

Na última década do século XX, teve início um intenso debate sobre a formação médica tradicional, posto que as escolas médicas em todo o País vêm sendo avaliadas com base em critérios emanados das demandas sociais em saúde e no que preceituam as novas Diretrizes Curriculares Nacionais para os cursos de Medicina, através das avaliações realizadas pelo SINAES (Briani, 2004).

Ribeiro (2002) afirma que as transformações sociais em saúde conduzem a alterações nas políticas públicas e nos mecanismos reguladores do setor, ao mesmo tempo em que engendram novas modalidades de organização dos serviços e de definição de novos espaços de cuidados à saúde. Nesse sentido, coloca-se em evidência a questão da legitimidade e da credibilidade das escolas médicas no que se refere aos requerimentos para a formação de novos profissionais médicos.

Segundo Amoretti (2005), para que essas transformações efetivamente ocorram, faz-se necessária a participação de todos os atores implicados nesse processo com vistas ao estabelecimento de uma nova ordem na formação médica. É preciso que as faculdades de Medicina obedeçam ao princípio da indissociabilidade entre ensino, pesquisa e extensão, pilar fundamental da prática docente universitária. Além disso, é preciso que se abram espaços de discussão e ação que contemplem as demandas dos serviços básicos de saúde, das unidades sanitárias, dos postos de saúde, dos pronto-atendimentos, das emergências, dos programas de assistência domiciliar e dos Centros de Atenção Psicossocial (CAPS), dentre outros.

Nas avaliações realizadas pelo SINAES nas escolas médicas de todo o Brasil, uma das constatações mais recorrentes diz respeito justamente ao não cumprimento do princípio referido anteriormente. Os cursos de Medicina, de maneira geral, mantêm suas formações quase exclusivamente baseadas no ensino (Aguiar, 2006).

A esse respeito, relatório elaborado pela Comissão Interinstitucional de Avaliação das Escolas Médicas (CINAEM), nos anos 90, indicou que os quadros docentes das escolas médicas brasileiras formados, em sua maioria, por especialistas, encontravam-se aquém das expectativas quanto ao atendimento das transformações em curso no País e que, portanto, estariam diante de uma grande dificuldade em adequar o ensino superior em Medicina às exigências preconizadas pelos mecanismos de avaliação institucional vigentes. 


\section{O SINAES e a avaliação institucional externa}

Ao SINAES, cuja supervisão e coordenação estão sob a responsabilidade da Comissão Nacional de Avaliação da Educação Superior (CONAES), compete estabelecer as diretrizes, os critérios e as estratégias dos processos avaliativos, em consonância com a Lei no. 10.861, de 2004, que o regulamenta.

Esse novo sistema integrou as avaliações de desempenho das instituições, dos cursos e dos estudantes a partir da análise de dez dimensões, avaliadas com base em conceituações numéricas em uma escala de um a cinco. Por meio dessa ponderação, os avaliadores oferecem uma análise global do desempenho das instituições de ensino superior (IES), estabelecendo quais são suas potencialidades, fragilidades e pontos que requerem melhorias e/ou adequações.

As avaliações são realizadas em três etapas: (a) uma autoavaliação conduzida pelas Comissões Próprias de Avaliação (CPAs) de cada instituição de ensino, (b) avaliações externas realizadas por comissões de docentes ativos, devidamente cadastrados e capacitados para tal, e (c) avaliação do desempenho dos alunos egressos dos cursos de graduação, feita por meio dos resultados das provas do Exame Nacional dos Discentes (ENADE) (Brasil, MEC/INEP2005).

No que tange aos procedimentos relativos à avaliação externa, os instrumentos disponibilizados pelo SINAES comportam critérios quantitativos e qualitativos para verificação do desempenho dos cursos universitários de graduação. Os dados quantitativos são fornecidos pelas próprias IES, através do preenchimento de formulário digital constante do sítio do Ministério da Educação e pelos membros que compõem as CPAs de cada curso (Brasil, MEC/INEP,
2005). Tais dados referem-se a determinadas dimensões, como estrutura material e física das instalações e recursos humanos, além de incluir informações provenientes do Censo da Educação Superior e de relatórios de avaliações anteriores.

As avaliações qualitativas, por sua vez, são feitas com base no referencial dos resultados quantitativos, mas são coadunadas com as verificações in loco realizadas por avaliadores externos. Essas visitas presenciais têm por objetivo dimensionar a capacidade real das instalações, a consonância entre a missão institucional e seu cumprimento efetivo e a adequação dos projetos pedagógicos dos cursos avaliados com o que determinam as Diretrizes Curriculares Nacionais para os cursos de graduação.

A esse respeito, Sguissardi e Júnior (2009 como citado em Silva, 2009, p.5), consideram que a CAPES e o CNPQ “(...) cumprem o papel de irradiação do ideário da reforma do Estado e da prática do Estado-gestor", do que resultam perda de autonomia do pesquisador e da produtividade acadêmica.

Motta (1981, p.5 como citado em Silva, 2009, p. 5), considera que a organização burocrática “(...) pretende se legitimar sob o argumento de suas pretensas racionalidade e neutralidade". A associação de tal lógica de gestão com a racionalidade mercantil é responsável pelo individualismo exacerbado constatado na Universidade, com implicações negativas na saúde mental dos docentes.

\section{A dimensão coletiva do trabalho}

Esse artigo filia-se a um determinado modo de fazer Psicologia do trabalho, que entende as questões da saúde, segurança, qualidade e produtividade como compatíveis. Além disso, o seu horizonte é a transformação positiva 
do trabalho, o que permite aos humanos e às organizações um desenvolvimento conjunto. As referências que nos auxiliaram no processo de análise dos dados provêm de algumas abordagens clínicas do trabalho (ergonomia e psicodinâmica do trabalho) que dão, cada uma a seu modo, um lugar de destaque à dimensão coletiva do trabalho.

Dentre as abordagens referidas, à ergonomia coube o pioneirismo no debate acerca dos aspectos coletivos do trabalho, com vistas a problematizar os processos de regulação, já que as situações de desfuncionamentos e de panes comumente estão relacionadas com questões coletivas partilhadas pelos operadores (Athayde, 1996).

A análise da dimensão coletiva do trabalho requer que se considerem duas noções essenciais: a tarefa coletiva prescrita, aquela que a organização estabelece, e a atividade coletiva, ou seja, a resposta dos agentes às solicitações da prescrição. Segundo Athayde, "ocorre atividade coletiva cada vez que a execução de uma tarefa ocasiona a intervenção coordenada de vários operadores" (1996, p. 62), e pode acontecer em um mesmo lugar ou em lugares diferentes. Vários indicadores permitem detectar a presença da atividade coletiva: as comunicações de uma equipe no curso do trabalho, a presença de regras destinadas a enfrentar os vazios (os imprevistos) da organização do trabalho e a adaptação do prescrito às condições da atividade, entre outras.

De acordo com Guérin, Laville, Daniellou, Duraffourg e Kerguelen (2001), as dimensões coletivas do trabalho podem se manifestar na colaboração explícita para a realização conjunta da mesma tarefa, nos resultados do trabalho, na atividade simultânea de trabalhadores, na busca de atingir objetivos diferentes, ou ainda nas atividades chamadas de regulação estrutural (aquelas em que certos trabalhadores exercem um papel organizador no tocante à atividade de outros).

Outra contribuição importante nessa discussão provém da psicodinâmica do trabalho, quando Cru (1986) formula a conceituação de coletivo de trabalho. Para esse autor, um coletivo se caracteriza pelo esforço conjunto e coordenado de trabalhadores que estariam empenhados em alcançar objetivos propostos a uma obra comum, observando-se o respeito às regras construídas coletivamente.

Essas regras não são evidentes nem estão explicitadas pela organização do trabalho; ao contrário, são estabelecidas espontaneamente e pressupõem uma concordância entre os trabalhadores no que se refere à elaboração de regulações próprias da profissão, e que determinam os limites, as possibilidades de ação, assim como e a gestão das imprevisibilidades colocadas pelas situações reais de trabalho (Cru \& Dejours, 1987).

Nessa perspectiva, a cooperação aparece como elemento fundante dos coletivos, na medida em que se constitui como os laços que constroem entre si os agentes que estão em vias de realizar, voluntariamente, uma obra comum, com o objetivo de fazer frente às insuficiências da organização do trabalho.

Embora considere que o foco da organização do trabalho sejam as relações de disciplina e poder e a demarcação de fronteiras de competência, é incontestável que esta última constitui um quadro de referência sem o qual a cooperação seria impossível, pois a ausência de parâmetros norteadores da ação cria um vazio que impede o exercício da capacidade inventiva dos trabalhadores.

A construção dos laços de cooperação exige que algumas condições sejam atendidas, pois é preciso que os modos de trabalhar de cada um sejam compartilhados, o que implica relações de confiança e espaços para 
confrontação de opiniões sobre a organização do trabalho no interior das empresas.

Segundo Dejours (2004), os trabalhadores respondem à coordenação prescrita da atividade a partir de uma cooperação efetiva. Entre as duas, interpõe-se uma série de iniciativas que, quando eficientes, conduzem à formação de regras de ofício, que constituem acordos entre os membros do coletivo a respeito das maneiras de trabalhar.

Lhuillier (2005) postula que o trabalho não é apenas organizado pelas direções e pelo enquadramento, mas é reorganizado por aqueles que o realizam. Essa reorganização pressupõe sempre uma construção coletiva baseada em decisões e deliberações conjugadas visando a regular as atividades individuais e, dessa maneira, inscrevê-las em um mapa significante comum a partir do qual algumas regras possam ser partilhadas. É, portanto, no coletivo de trabalho que tem lugar esse trabalho de reorganização da tarefa, tendo por base um corpo partilhado de regras. Por essa razão, a autora sustenta que trabalhar comporta uma dimensão material (produção), mas envolve também relações intersubjetivas, a partir das quais se revelam os limites e as capacidades de cada um, e que são essenciais à validação coletiva das contribuições singulares.

\section{Método}

O estudo, do qual o presente artigo é uma expressão, utilizou a abordagem qualitativa, em razão do interesse em aproximar-se das experiências subjetivas dos participantes acerca do trabalho docente, e foi realizado com professores do curso de Medicina de uma IFES, do qual fazem parte 149 docentes distribuídos em 7 departamentos. O grupo de pesquisa foi composto por 10 docentes, 2 mulheres e 8 homens, com idades que variaram entre 45 e 63 anos e tempo médio de exercício como docente de 21,1 anos.
Devido às dificuldades de tempo de alguns docentes em participarem da pesquisa, buscou-se estabelecer contatos com aqueles que se envolveram no último processo de avaliação institucional, tornando-se esse o principal critério para a composição do grupo de pesquisa.

A participação de todos os voluntários levou em consideração os aspectos éticos pertinentes à investigação que envolve seres humanos, conforme a Resolução no. 196/96, do Conselho Nacional de Saúde (CNS). Apenas após a aprovação do projeto de pesquisa pelo Comitê de Ética e a assinatura do Termo de Consentimento Livre e Esclarecido (TCLE) pelos participantes é que teve início a pesquisa propriamente dita.

O instrumento de coleta de dados foi a entrevista não diretiva, que, segundo Thiollent (1987), não propõe ao entrevistado uma estruturação completa do campo de investigação, uma vez que é este quem detém a atitude de exploração do tema lançado pelo pesquisador.

As entrevistas foram realizadas nas dependências da IFES, durante o horário de trabalho dos docentes, no período de novembro de 2006 a fevereiro de 2007, e duraram em média 50 minutos cada. Tais entrevistas foram gravadas e depois transcritas e submetidas ao processo de análise de dados.

A análise das informações pautou-se na técnica da análise da enunciação, que parte de uma concepção de discurso como palavra em ato, ou seja, que concebe a produção da palavra como um processo, "não como um produto acabado, mas um momento num processo de elaboração, com tudo o que isso comporta de contradições, de incoerências e de imperfeições" (Bardin, 1977, p. 170).

Além das entrevistas, foram utilizados como 
fonte de informações os relatórios da última avaliação institucional externa realizada pelo MEC no início de 2005.

\section{Resultados}

As análises realizadas permitiram construir uma determinada visão da atividade docente universitária no curso pesquisado, que evidenciou algumas peculiaridades desse meio profissional. Nesse sentido, as abordagens clínicas escolhidas mostraramse ferramentas importantes na análise dos dados, sobretudo no que concerne à importância dos coletivos de trabalho.

\section{A organização do trabalho no curso de Medicina}

\section{Os dilemas do modelo de gestão vigente}

Compartilha-se com Dejours (1992) a tese de que a organização do trabalho, compreendida como divisão do trabalho (atribuição de tarefas, repartição das responsabilidades) e divisão dos homens (hierarquia, comando, distribuição do poder), tem forte implicação no funcionamento psíquico.

Apesar de fixada na disciplina, no controle e no poder, a organização do trabalho é uma referência fundamental para os trabalhadores, pois permite o exercício da inteligência na busca de soluções para os problemas gerados pelas insuficiências e lacunas da previsão.

No caso aqui analisado, é preciso situar, no que se refere à organização do trabalho, que os sete departamentos do curso funcionam como unidades autônomas, e cada uma mantém chefias e organizações próprias em torno das especialidades médicas por que são responsáveis. Essa condição coloca, de partida, dificuldades à construção de um projeto coletivo, pois, em uma estrutura tão fragmentada, observa-se que é reduzida a capacidade de perceber a formação médica em sua globalidade, especialmente se considerarmos a fragilidade dos mecanismos de comunicação interdepartamental existentes no curso.

A situação descrita favorece o isolamento de cada unidade, levando-as a perder de vista o projeto maior que as une e, sobretudo, o destinatário de tal projeto, que é o aluno de Medicina. O depoimento abaixo dá conta da dificuldade gerada por esse modelo de gestão.

Olhe, fica muito, muito difícil fazer um trabalho conjunto (...) aqui tudo é dissociado, sabe? Essa estrutura cêntrica, departamental (...) Na verdade, essa estrutura isola muito. Aqui em Medicina, tudo é dissociado. Parecem vários cursos dentro de um curso. Não tem regras claras de execução do trabalho, entende? Se você me perguntar como os meus colegas de departamento trabalham, eu não vou saber responder. ( F, mulher, 56 anos).

A estrutura cêntrica ou departamental configura-se como modelo de gestão predominante na IFES onde foi feita a pesquisa. As queixas sobre os efeitos negativos desse modelo são compartilhadas por outros cursos da mesma universidade. Tal fato motivou, inclusive, o reitorado atual a incluir, no seu programa de governo, a revisão desse modelo de gestão que, entretanto, ainda sobrevive sem alterações. Por outro lado, a constatação de que existem "vários cursos dentro de um curso" testemunha a fragilidade, conforme apontado anteriormente, dos mecanismos de comunicação interdepartamental, cuja conseqüência mais evidente é a dificuldade, ou mesmo a impossibilidade de construir regras comuns que orientem a conduta dos docentes. Disso resulta uma variedade de orientações nascidas no interior de cada departamento, muitas vezes conflitantes, que repercutem na produtividade e na qualidade do trabalho realizado. 


\section{Os vazios organizacionais}

Embora Dejours (1992) afirme que a organização do trabalho privilegia a disciplina, as relações de poder e a divisão do trabalho, ele a entende como um referencial indispensável à existência da cooperação, pois representa a base sob a qual é possível criticar, transgredir, reformular e inovar, sempre a partir dos desafios que a atividade suscita. A organização do trabalho constitui, nesse sentido, não apenas um constrangimento, uma limitação, mas um recurso que desafia a inteligência em busca de novas soluções para os problemas que se apresentam no cotidiano. Entretanto, quando faltam as diretrizes, quando o quadro organizacional é opaco, recheado de vazios, as possibilidades de cooperação e, em conseqüência, de constituição e de manutenção de coletivos se monstram bastante reduzidas, abrindo espaço para a individualização.

Esse vazio de diretrizes autoriza um semnúmero de formas de trabalhar, que alguns chamam de autonomia, mas que, na verdade, testemunha a dispersão, a individualização, a perda de foco, com conseqüências deletérias na saúde (mental) e na produtividade e qualidade do trabalho. Dispor de um quadro organizacional claro e da possibilidade de reajustá-lo permanentemente é, sem dúvida, uma situação mais favorável à conquista de um meio de trabalho saudável e produtivo.

Eu acho que a pior forma de organização do processo de trabalho é a do (...) fordismo deturpado, não é? Que você pega, divide o conteúdo programático de uma disciplina (...) ah! Fulano vai dar isso, sicrano aquilo (...) e cada um faz, dá do seu jeito e outro não pode interferir e não há nenhuma discussão sobre a forma de abordar as didáticas, etc. ( O, homem, 47 anos).

A não participação de alguns docentes nas instâncias de regulação coletiva (como as reuniões de departamento e do colegiado do curso), onde poderiam ser debatidos assuntos pertinentes ao ensino, à pesquisa $\mathrm{e}$ à extensão, acarreta dificuldades ao processo de gestão coletiva da atividade docente. A ausência de regras comuns abre espaço ao descompromisso, ao isolamento por áreas de atuação, à existência de múltiplas formas de atuação, o que gera desequilíbrios na divisão do trabalho, que pesam particularmente sobre os docentes que ocupam cargos de chefia.

As relações que a gente tem aqui são assim (...) do ponto de vista individual, de se cumprimentar, de ser cordial, quase todo mundo aqui se relaciona maravilhosamente. Mas, no momento em que a gente vai debater alguma coisa relacionada à prática docente, ao que está errado, ao que deve ser melhorado para o bem do curso como um todo... aí a relação muda (...). Aqui as pessoas só se juntam, trabalham juntas na hora de reivindicar aumento no salário. Aí todo mundo se junta, vai pras assembleias de indicativo de greve (...) só se unem assim (...). (X, mulher, 53 anos).

A gente muito mal consegue fazer reunião de departamento. Isso traz grandes problemas, porque qualquer coisa que a gente solicita do ponto de vista administrativo, é complicado ser atendido. ( $\mathrm{Y}$, homem, 48 anos).

Sabe-se que cotidianamente os trabalhadores, nos seus encontros informais, discutem sobre o trabalho e as dificuldades que enfrentam. Desses encontros, nascem certamente soluções originais para os problemas enfrentados. Não obstante, é preciso que os representantes da organização tomem a iniciativa de instituir espaços públicos, de modo que essas soluções, muitas vezes operadas na clandestinidade, sejam conhecidas e debatidas por todos e de onde possam surgir regras que orientem a conduta dos coletivos.

Dejours (1993) propõe que sejam viabilizados espaços públicos de discussão, em que trabalhadores e hierarquia possam discutir, que denomina espaço público, ou seja, um ambiente em que as insuficiências da organização do trabalho possam ser questionadas e debatidas e, em torno delas, 
construídos acordos sobre os modos de enfrentá-las.

Um pré-requisito para que esses espaços cumpram efetivamente o seu papel é que existam relações de confiança, que possibilitem a comunicação intersubjetiva, a demonstração dos modos de fazer e de proceder de cada um, por fim, a elaboração de um referencial comum que paute as escolhas individuais.

\section{Autonomia no trabalho $X$ individualização}

Autonomia, na visão de alguns docentes, significa a liberdade de proceder da forma que julgar mais conveniente, ainda que entre em choque com parâmetros institucionais. A autonomia se manifesta, conforme Clot, (2006) na contribuição que cada um oferece frente às solicitações da atividade, ao aperfeiçoamento do gênero profissional. A falta de acordos sobre as formas de trabalhar, como pontua Dejours (2004), leva à dissolução dos coletivos, ao isolamento, o que traz reflexos negativos para a construção de um projeto coletivo.

Hoje o professor é extremamente autônomo. Ele faz o que ele quer na sala de aula. A gente está com um currículo extremamente defasado (...). Desde que as novas diretrizes foram lançadas que a gente tenta levantar essa discussão no curso, mas são sempre movimentos muito tímidos, frágeis, mesmo. E a gente não consegue implantar essas mudanças, que são muito necessárias, porque os professores não aderem, não discutem, e fica por isso mesmo. Você convoca uma reunião, ninguém vem, e fica por isso mesmo. (K, homem, 50 anos).

(...) quanto à autonomia, ela é maravilhosa, mas se for bem utilizada. O que acontece é que estão fazendo mau uso dessa liberdade. Ela é maravilhosa para quem tem responsabilidade. Só que essa cultura da não cobrança, de você não usar de responsabilidade e você não ser punido, ela tem se perpetuado, e ela está se agravando. Na medida em que você não tem nenhum mecanismo de cobrança (...), você pinta e borda. A realidade é essa. Então, esse mau uso da liberdade está fazendo com que você leve para uma situação de descrédito tal, que você diz: 'olha, eu vou fazer mais pra quê, se ninguém está fazendo e não está sendo cobrado'. (F, mulher, 56 anos).

As observações revelam que a autonomia se apresenta sob a condição de dominar o gênero, ou seja, da incorporação de formas de trabalhar e de se comportar nas relações sociais que o tempo registrou como válidas para compor o patrimônio de um determinado meio profissional. É um estoque a ser usado, um costume que permite economizar energia em direção ao alvo. Quando o gênero está ausente, entretanto, assiste-se a uma desregulação da atividade individual, uma proliferação de condutas que mais espelham a desorientação das pessoas do que manifestação subjetiva saudável (Clot, 2006).

Visitando a literatura que trata da questão da autonomia, encontramos o entendimento de que esta significa a capacidade de produzir suas próprias regras. No entanto, é preciso reconhecer que "nenhum processo de ação social pode ser completamente autônomo, pelo fato de estar em relação com outros processos..." (Maggi, 2006, p.139), razão pela qual autonomia e heteronomia são duas faces da mesma moeda. A organização do trabalho, na medida em que representa a vontade de outrem, situa-se no polo heterônomo. Os coletivos de trabalho, na medida em que retraduzem a organização do trabalho e contribuem para compensar as suas insuficiências, norteadas por regras negociadas, representam o polo da autonomia.

Kovács entende autonomia, em sentido estrito, como a liberdade no exercício das funções e na realização das tarefas. No sentido lato, a autonomia no trabalho pode ser definida como um

(...) espaço de decisão e intervenção nos processos de trabalho, abrangendo 
também a possibilidade de autocontrole e auto-avaliação e, ainda, a participação na organização e no funcionamento da empresa, bem como a oportunidade de influenciar as decisões sobre mudanças na organização do trabalho e nas condições de trabalho em geral (2006, pp. 41-42)

Segundo Ollivier, "pensar a autonomia é pensar as suas relações com os outros, com a dupla finalidade de não lhes ficar submetido e de lhes mostrar os benefícios que podem retirar da autonomia" (2005, p.24). A busca de autonomia de cada sujeito (que nasce sob o signo da heteronomia) pressupõe a impressão de mudanças na economia psíquica, o que exige um trabalho de desconstrução das representações interiorizadas pelo outro.

De acordo com Dejours (1992), os laços de cooperação são fundamentais para constituir coletivos de trabalho que, por sua vez, cumprem a função de proteger as regras construídas pelos próprios trabalhadores contra as ameaças externas e internas. Assim, uma organização do trabalho que cria obstáculos à formação desses coletivos promove desestabilização, podendo inclusive inviabilizar as possibilidades de cooperação entre os trabalhadores. Como vimos, a proliferação de condutas, de modos de proceder nas situações de trabalho testemunha mais uma individualização, a ausência de um referencial comum do que uma autonomia autêntica. Esta nasce nos espaços públicos, em que a palavra é franqueada e onde são gerados acordos sobre os modos coletivos de encaminhar-se em face dos desafios no trabalho.

\section{A questão da formação}

\section{Indissociabilidade ensino, pesquisa e extensão}

No que tange ao princípio da indissociabilidade entre ensino, pesquisa e extensão, há discordâncias tanto de compreensão quanto de operacionalização. Na ausência de um pacto conceitual e operacional, o que se constata é o predomínio de um dos termos desse tripé (o ensino), em detrimento dos outros dois.

Olha, esse negócio de indissociabilidade, sabe (...) isso vai depender do departamento. Aqui mesmo, no nosso, isso é uma coisa que ainda se faz com muita dificuldade. Está lento. Por que o que a gente quer é que o aluno saia sabendo do básico, que vem com as aulas. (B, homem, 55 anos).

Essa situação foi detectada pelos avaliadores do MEC, que observaram que a ênfase no ensino se dá em detrimento da dedicação à pesquisa, fato constatado por meio de uma produção científica muito abaixo da esperada para um grupo de 149 docentes. Desses, apenas $6 \%$ se dedicavam a atividades de pesquisa e extensão. Além disso, o investimento na formação em nível de pós-graduação (excetuando-se as residências) tanto stricto sensu quanto lato sensu é praticamente nulo, o que reforça o diagnóstico de desequilíbrio no tripé da indissociabilidade.

Esse é, inclusive, um dos grandes problemas nos cursos de Medicina (...) que estão quase resumidos ao ensino. Inclusive, na última avaliação do curso (...) feita pelo INEP, no relatório, tinha uma situação de um percentual muito pequeno dos docentes que faziam pesquisa, ensino e extensão, enquanto o restante só fazia sala de aula (...). Outro grande problema (...) a Medicina não tem nenhuma pós-graduação, é um dos poucos cursos da universidade que não tem uma pós-graduação, (...) fora as residências, que é a nível de lato sensu. E, na hora que você pensa montar, isso é supercomplicado, porque os Doutores não querem participar. (Y, homem, 48 anos).

Esse fato é preocupante em um contexto em que a atividade docente não figura como a atividade principal, mas subsidiária da prática médica, em geral desenvolvida fora dos muros da Universidade. É o exercício profissional 
externo, portanto, que confere status e autoridade ao docente no curso de Medicina. O ensino situa-se, nesse contexto, como o alvo principal, alimentado prioritariamente pela prática profissional, razão pela qual, como se verá adiante, o gênero profissional médico vê com reservas a opção pela dedicação exclusiva.

Nesse sentido, a experiência intramuros não tem o mesmo valor que aquela conquistada nos consultórios e nas clínicas externas. Enxergamos aqui, ao que parece, a predominância do gênero profissional médico sobre o gênero profissional docente. $\mathrm{O}$ primeiro só confere valor àquele que conjuga uma prática profissional externa com a docência, apresentando-se, em função disso, forte, poderoso e suficientemente capaz de orientar as condutas dos docentes.

O gênero profissional docente ocupa um lugar secundário, apresentando-se desfigurado e impotente para orientar as condutas dos docentes. Aqueles que se colocam na contramão do gênero profissional médico e priorizam a pesquisa ou a extensão se sentem diminuídos, desprestigiados, inclusive junto aos alunos.

Eu já tô cansado aqui de ser chamado de Bacharel em Medicina, no sentido pejorativo, mesmo! Porque eu optei em me dedicar à carreira docente, à pesquisa. Eu fiz meu mestrado, estou no doutorado... eu espero ver o curso de Medicina produzindo cientificamente... deixando um legado. Mas quem reconhece isso?... Eu não tenho como me projetar atendendo no HU, né? Não tem espaço pra isso. (W,homem, 47 anos) O professor bom, aqui, reconhecido pelos colegas e pelos alunos, é o que é médico, que tem prática lá fora. (X, mulher, 53 anos)

Nesse sentido, a ergologia (Schwartz \& Durrive, 2007) fornece indicações que podem representar saídas para esse dilema e que caminham no mesmo sentido da indissociabilidade. De acordo com essa abordagem, existem, de um lado, as normas antecedentes, ou seja, o patrimônio conceitual, o legado científico, as técnicas, os procedimentos, enfim, toda essa herança que deve ser dominada por meio de uma boa transmissão (a ênfase no ensino), e, de outro lado, a atividade, a prática (intra ou extramuros universitários), o confronto com os desafios do cotidiano profissional, que exige interpretações e decisões contingentes e que são, igualmente, insumos fundamentais ao ensino, pois permitem a crítica desse patrimônio conceitual, aperfeiçoando-o e refinando-o.

Ao enfatizarmos um ou outro polo, assumimos posições extremadas e nos empenhamos em uma peleja entre os teóricos e os práticos, cujos efeitos negativos os depoimentos dão fartos exemplos.

Entretanto, se optarmos por colocar em diálogo esses polos, sustentados por uma humildade epistêmica, abre-se a possibilidade de fertilizações recíprocas, oferecendo assim outra saída ao impasse, com consequências positivas para ambos. O regime de produção de conhecimentos necessita tanto dos saberes da experiência quanto dos saberes acadêmicos. O diálogo desses saberes, condição fundamental para produzir um conhecimento inédito sobre a atividade humana de trabalho (Durrive \& Schwartz, 2008), supõe de parte a parte uma humildade epistêmica, ou seja, uma disponibilidade e uma abertura ao diálogo que reconheça que ambos os saberes (conhecimento e experiência) vivem a fragilidade de não explicar a realidade em sua totalidade, sendo complementares, e não, excludentes (Borges, 2005).

A organização do trabalho, encarnada tanto na gestão superior da Universidade (reitor, pró-reitores, diretores de centro) quanto na gestão local (chefias de departamento), pode desempenhar um papel importante, seja na institucionalização de espaços de debates, 
seja investindo no processo de reformulação organizacional, que permita superar as barreiras de comunicação atuais, que tantas dificuldades trazem à construção de um ideário e de um projeto comum.

\section{A questão da formação médica}

Todas as dificuldades apontadas pelos participantes foram evidenciadas na última avaliação do MEC/INEP em 2005. As constatações referentes ao isolamento das unidades departamentais e a fragilidade dos elos de cooperação entre elas colocaram em evidência a dificuldade de construção de um projeto comum para o curso.

No que concerne às exigências de mudanças na formação médica em consonância com as novas Diretrizes Curriculares Nacionais, a maioria dos docentes, excetuando-se aqueles que tiveram participação efetiva no processo de avaliação, declarou desconhecer as discussões e os encaminhamentos relativos a essa questão. Um dos entrevistados, ao ser questionado sobre os rumos da reforma (que inclui a tentativa em agregar a pesquisa e a extensão à educação médica), por meio de uma inserção precoce nos serviços de atenção básica à saúde, assim se posicionou:

Eu estou muito à parte disso aí. Eu tenho escutado essas divagações, mas com muito, com muito receio. Como sempre, as coisas aqui são muito de cima pra baixo. E não escutam muito os docentes nessa história. Tudo aqui é feito de cima pra baixo. Vem do MEC, vem do Ministério da Saúde, vem num sei de onde... Eu acredito que esse negócio não sai do papel nem tão cedo. (J, homem, 52 anos).

Por outro lado, um docente que teve participação ativa no processo de avaliação do curso afirmou que o desconhecimento, pela maioria dos docentes, das mudanças que devem ser promovidas em todas as faculdades de Medicina do Brasil dificulta a concretização das propostas do SINAES.

O entrave à efetivação dessas mudanças, conforme declarou outro entrevistado, decorre de uma forte resistência originada nos docentes ligados ao modelo antigo de formação, já que a proposta atual é a de mudança de paradigma, e não somente de disciplinas em um currículo.

Eu acho que o grande problema é exatamente isso, essa mudança paradigmática que os docentes não querem fazer, porque, nas novas Diretrizes, coloca-se como uma vertente principal a aproximação do ensino da prestação de serviços, da realidade concreta de atendimento que o País tem. (...) inclusive, coloca como cenário de prática não mais (...) o hospital como centro da formação, mas coloca todos os serviços de saúde. Isso requer um novo, um outro tipo de engajamento docente, que não é vir simplesmente aqui, dar sua aulinha e ir embora. Requer um processo de acompanhamento do aluno no serviço, tem que se deslocar daqui para outros campos de atividades. (W, homem, 47 anos).

Finalizando, Amoretti, em estudo sobre as novas tendências da educação médica, corrobora a visão de que os docentes dos cursos de Medicina ainda não estão dispostos a realizar as reformulações no modelo de formação vigente. Essas modificações, ancoradas no compromisso com os princípios do SUS, não serão facilmente implementadas em virtude de um posicionamento políticoideológico dos docentes que os afastam da saúde coletiva, no que se refere à prevenção e à promoção à saúde. Acrescenta o autor que há, por parte desses professores, um movimento resistente às mudanças e em defesa de um status quo vigente.

Esse engajamento docente? Com essas mudanças das Diretrizes Curriculares? Ah, eu acho muito difícil mudar de verdade, viu. Muda só no papel, mas o pensamento 
do professor médico é continuar a prática do consultório, do hospital (...) não tem essa mudança de pensamento pra uma prática que seja mais da prevenção e da promoção (...) Isso o Ministério da Saúde quer, o MEC quer, mas o professor de Medicina eu não sei se quer, não (...) é difícil. (V. homem, 60 anos).

\section{Considerações finais}

O objetivo deste artigo foi analisar questões relativas à gestão coletiva da atividade docente, evidenciadas no processo de avaliação externa do curso de Medicina de uma IFES.

Nas avaliações realizadas nas escolas médicas de todo o Brasil, uma das constatações mais frequentes diz respeito ao descumprimento do princípio da indissociabilidade entre ensino, pesquisa e extensão, priorizando-se quase exclusivamente o ensino. Concorre para essa situação o fato de a maioria dos docentes das escolas médicas considerar a docência uma atividade secundária em relação à prática médica, que acontece fora dos muros universitários. A pesquisa e a extensão só merecem a atenção de minoria de docentes, em geral regidos pela dedicação exclusiva, uma opção não muito bem vista pela maioria dos docentes. Tal situação em que se coloca, de um lado, a prática e, do outro, a transmissão, o ensino, subordinandose o segundo ao primeiro termo, cria um tipo de cisão que pouco contribui para o avanço do conhecimento. Sabemos, com a ergologia, que esse tipo de oposição entre práticos e teóricos não leva a lugar algum. A organização do trabalho pode desempenhar, nesse sentido, um papel fundamental na proposição de uma alternativa que, ancorada no diálogo, ofereça um destino mais favorável a esse impasse. Pelo que pudemos perceber, há que se repensar o modelo de gestão universitária nessa IFE, responsável, em parte, pelo menos, por esse estado de coisas. Outra discussão que merece ser travada diz respeito à avaliação do trabalho, o que inclui, mas não se confunde com a avaliação do desempenho.

Um processo de avaliação que se pretenda transformador deve distanciar-se do caráter punitivo e da mera identificação de falhas para fortalecer as potencialidades de todos os atores sociais. Os docentes entrevistados apontam a necessidade de repensar a atividade docente, a fim de que esta se realize em um processo de construções efetivas do trabalho, com ênfase na coletividade e na cooperação, aspectos essenciais à comunicação entre os diversos segmentos acadêmicos e sociais.

Ao invés do conflito, da disputa entre os gêneros, uma saída mais favorável é sem dúvida a negociação, a busca de um caminho que respeite as particularidades de cada gênero, escapando-se, assim, de uma situação hierarquizada, de dominação do gênero médico sobre o gênero docente, como a que se apresenta atualmente.

Os problemas da gestão coletiva se exacerbam com as novas Diretrizes Curriculares para os cursos de Medicina, que pretendem fazer com que esses cursos se voltem para as demandas sociais em saúde. Estabelece-se, nesse caso, um conflito político-ideológico, de concepções, de práticas, que nos parece difícil de superar apenas com uma mudança nas Diretrizes Curriculares. Nesse caso, outras ações precisariam ser desenvolvidas para que mudança de tal magnitude fosse implementada.

A esse respeito, o relatório da Comissão Interinstitucional Nacional de Avaliação das Escolas Médicas - CINAEM (1999) indicou que os quadros docentes das escolas médicas brasileiras formadas, em sua maioria, por especialistas, encontravam-se aquém das expectativas no tocante às transformações em curso no País e que, portanto, estariam diante de uma grande dificuldade em adequar 
o ensino superior em Medicina às exigências preconizadas pelos mecanismos de avaliação institucional vigentes. O desconhecimento de grande parte dos docentes das mudanças que devem ser promovidas em todas as faculdades de Medicina do Brasil dificulta a concretização das propostas do SINAES.

Dessa forma, o entrave à efetivação dessas mudanças decorre de uma forte resistência originada em alguns docentes ligados ao modelo antigo de formação, já que a proposta atual é a de uma mudança de paradigma, e não somente de disciplinas em um currículo. No entanto, é preciso frisar que os resultados foram elucidativos no tocante à compreensão das particularidades da docência em Medicina e das dificuldades vividas pelos docentes na realização de suas atividades.

\section{Elvia Lane Araújo do Nascimento}

Mestre em Engenharia de Produção pela Universidade Federal da Paraíba.Professora Assistente I da

Universidade Federal de Campina Grande/Departamento de Psicologia, Campina Grande - PB - Brasil..

E-mail: elvianascimento@yahoo.com.br

\section{Sarita Brazão Vieira}

Doutora em Saúde Mental pela Universidade Federal do Rio de Janeiro. Professora associada da Universidade Federal da Paraíba/Departamento de Psicologia, João Pessoa - PB - Brasil.

E-mail: sarita@terra.com.br

\section{Anísio José da Silva Araújo}

Doutor em Saúde Pública pela FIOCRUZ. Professor associado da Universidade Federal da Paraíba/ Departamento de Psicologia, João Pessoa - PB Brasil.

E-mail: anisiojsa@uol.com.br

Endereço para envio de correspondência:

Rua Riachuelo, 1411, Jardim Paulistano, Campina Grande/Paraíba. CEP: 58.461-105

Recebido 21/06/2010, 1aㅡ Reformulação 31/10/2011, Aprovado 21/06//2012. 


\section{Referências}

Aguiar, A. C. (2006). Cultura de avaliação e transformação da educação médica: a ABEM na interlocução entre academia e governo. Revista Brasileira de Educação Médica, 30(02), 98-101. Recuperado em 02 fev., 2007, de www.abemeducmed.org.br/rbem.

Alvarez, D. (2004). Cimento não é concreto, tamborim não é pandeiro, pensamento não é dinheiro. Pra onde vai à produção acadêmica? Rio de Janeiro: Myrrha.

Amoretti, R. (2005). A educação médica diante das necessidades sociais em saúde. Revista Brasileira de Educação Médica, 29(02), 136-146. Recuperado em 13 mar., 2006, dewww. abem-educmed.org.br/rbem.

Associação Brasileira de Educação Médica. (1999). Comissão Interinstitucional Nacional de Avaliação das Escolas Médicas (CINAEM). Recuperado em 11 de mar., 2006, de www.abemeducmed.org.br/cinaem.php.

Athayde, M. (1996). Gestão de coletivos de trabalho e modernidade: questões para a engenharia de produção. Tese de doutorado. COPPE, Universidade Federal do Rio de Janeiro, RJ.

Bardin, L. (1977). Análise de conteúdo. Lisboa: Edições 7.

Borges, M. E. S. (2005). Trabalho e gestão de si - para além dos "recursos humanos". Cadernos de Psicologia Social do Trabalho, 7, 41-49.

Brasil. Ministério da Educação/ Instituto Nacional de Pesquisas Educacionais Anísio Teixeira. (2005). Avaliação externa de instituições de educação superior: diretrizes e instrumentos. Recuperado em 17 nov., 2006, de www.mec.gov.br/inep.

Briani, M. C. (2004) O ensino médico no Brasil está mudando? Revista Brasileira de Educação Médica, 25(03), 73-77. Recuperado em 28 dez., 2006, de www.abem-educmed. org.br/rbem

Brito, J., Athayde, M., \& Neves, M. Y. (Orgs.). (2003). Cadernos de relatos de experiências: programa de formação em saúde, gênero e trabalho nas escolas. João Pessoa, PB: Editora Universitária, UFPB.

Conselho Nacional de Saúde (CNS). (1996). Sobre pesquisa envolvendo seres humanos. Resolução no 196/96. Recuperado em 17 nov., 2006, de http://conselho.saude.gov.br/ resolucoes/1996/Reso196.doc.

Cru, D. (1986). As regras do ofício. In Dejours, C. (Org.). Plaisir et souffrance dans le travail (pp. 29-42). Paris: AOCIP; São Paulo: Mimeo.

Cru, D., \& Dejours, C. (1987). Saberes de prudência nas profissões da construção civil: nova contribuição da psicopatologia do trabalho à análise da prevenção de acidentes na construção civil. Revista Brasileira de Saúde Ocupacional, 13(59), 30-34.

Cunha, M. I., \& Leite, D.B.C. (1996). Decisões pedagógicas e estruturas de poder na universidade. Campinas, SP: Papirus.

Clot, Y. (2006). A função psicológica do trabalho. Petrópolis, RJ: Vozes.

Dejours, C. (1992). A loucura do trabalho: estudo de psicopatologia do trabalho (5a. ed.) São Paulo: Cortez-Oboré.

Dejours, C. (1993). Coopération et construction de l'identité en situation de travail. Recuperado em 31 ago., 2009, de http://multitudes.samizdat.net/coopération et construction de l'identité en situation de travail.

Dejours, C. (2004). Patologia da comunicação. Situação de trabalho e espaço público: a geração da energia com combustível nuclear. In S. Lancman \& L. I. Sznelwar,
Christophe Dejours - da psicopatologia à psicodinâmica do trabalho (pp. 243-275). Rio de Janeiro: Editora Fiocruz, Brasília,DF: Paralelo 15.

Durrive, L., \& Schwartz, Y. (2008). Glossário da ergologia. Laboreal, 4(1), 23-28. Recuperado em 02 de fev., 2007 de http://laboreal.up.pt/revista/artigo.php?id=48u56oTV 6582234396587;63882Guérin, F., Laville, A., Daniellou, F., Duraffourg, J., \& Kerguelen, A. (2001). Compreender o trabalho para transformá-lo - a prática da ergonomia. São Paulo: Edgard Blücher.

Kovács, I. (2006). Novas formas de organização no trabalho e autonomia no trabalho. Sociologia, Problemas e Práticas, 52, 41-65.

Lampert, J. B. (2001). Currículo de graduação e o contexto da formação do médico. Revista Brasileira de Educação Médica, 25(01), 07-19. Recuperado em 28 dez., 2005, de www. abem-educmed.org.br/rbem.

Lhuillier, D. (2005). Trabalho. In J. Barus-Michel, E. Enriquez, A Lévy (Orgs.). Dicionário de Psicossociologia (pp. 210-219). Lisboa: CLIMEPSI.

Machado, A. R., \& Magalhães, M. C. C. (2002). A assessoria a professores na universidade brasileira: a emergência de uma nova situação de trabalho a ser desvelada. In D. Faïta \& $M$. C. P. Souza-e-Silva, M. C. P. (Orgs.), Linguagem e trabalho: construção de objetos de análise no Brasil e na França (pp. 139-156). São Paulo: Cortez Editora.

Maggi, B. (2006). Do agir organizacional. São Paulo: Edgard Blücher.

Morosini, M. C. (2004). Educalização superior e transnacionalização: avaliação/qualidade/ acreditação In D. Mancebo \& M. L. A. Fávero (Orgs.), Universidade: políticas, avaliação e trabalho docente (pp. 145-170). São Paulo: Cortez. Editora.

Moré, N. C., \& Gordan, P. A. (2004). A percepção dos professores do departamento de medicina da Universidade Estadual de Maringá sobre suas dificuldades e necessidades educacionais para o desenvolvimento do ensino médico. Revista Brasileira de Educação Médica, 28(03), 215-222. Recuperado em 28 dez., 2005, de www.abem-educmed.org.br/rbem.

Ollivier, B. (2005). Autonomia. In J. Barus-Michel \& E. Eugène A. Lévy. (Coords.). Dicionário de Psicossociologia (pp. 24-32). Lisboa: CLIMEPSI.

Ribeiro, E. C. O. (2002). A educação dos profissionais de saúde na América Latina: teoria e prática de um movimento de mudança. Interface - Comunicação, Saúde e Educação, 04(04), 139-142.

Sá Júnior, L. S. (2002). Ética do professor de medicina. Revista de Bioética e Ética Médica, CFM, 10(1), 49-84.

Schwartz, Y., \& Durrive, L. (Orgs.). (2007). Trabalho e ergologia: conversas sobre a atividade humana. Niterói, RJ: EDUFF.

Silva, P. E. (2009). Gestão heterônoma e trabalho docente. In VII Seminário Nacional de Estudos e Pesquisas História, Sociedade e Educação no Brasil. VIII Seminário Nacional de Estudos e Pesquisas História, Sociedade e Educação no Brasil - História, Educação e Transformação, (v. 1, 1-25), Campinas, SP : HISTEDBR.

Thiollent, J. M. (1987). Critica metodológica, investigação social e enquête operária (5a. ed.) São Paulo: Polis. 